\title{
Interspinous Process Implants Causes Wear of the Spinous Processes in Patients Treated for Spinal Stenosis-An Experimental Biomechanical Study with Comparison to Clinical Cases
}

\author{
Adad Baranto*, Christian Hagelberg, Jonas Hvannberg, Lars Ekström, Klas Halldin, \\ Helena Brisby \\ Department of Orthopaedics, Institute of Clinical Sciences at Sahlgrenska Academy University of Gothenburg \\ and Sahlgrenska University Hospital, Gothenburg, Sweden \\ Email: *adad.baranto@vgregion.se,Christian.hagelberg@vgregion.se, lars.ekstrom@orthop.gu.se, \\ kh@khalldin.se, helena.brisby@vgregion.se
}

Received 12 June 2016; accepted 11 July 2016; published 14 July 2016

Copyright (C) 2016 by authors and Scientific Research Publishing Inc.

This work is licensed under the Creative Commons Attribution-NonCommercial International License (CC BY-NC).

http://creativecommons.org/licenses/by-nc/4.0/

(c) (i) (9) Open Access

\section{Abstract}

There are few biomechanical studies on Interspinous Process Implants (IPD); however none investigate the amount of wear on spinous processes. Therefore the objective of the present study was to investigate the effect of repetitive loading of the IPD Aperius on the spinous processes in a biomechanical porcine model. For comparison, three patients treated surgically with the same device have been followed for one to two years clinically and with image analyses (X-rays, MRI, CT-scans). Four lumbar spines from 6 months old porcine were divided into seven segments, which received IPD. The segments were exposed to 20,000 cyclical loads. Afterwards the deformation (wear) of the segments was registered. The wear of the spinous processes was measured in $\mathbf{m m}$ on a following CT-scan. Additionally, the wear of the ex-vivo was compared to that of the spinous processes investigated by CT-scans or X-ray in three patients treated surgically with the same interspinous implant. The mean maximal deformation of porcine specimens was $1.79 \mathrm{~mm}$ (SD 0.25) with the largest deformation occurring in the first quarter of the loading ( $<5000$ cycles). The mean wear of the spinous processes after loading was $6.57 \mathrm{~mm}$. A similar level of wear (mean $12.7 \mathrm{~mm}$ ) of the spinous processes was detected in the patients. The Aperius IPD creates significant wear on the spinous processes in an experimental biomechanical study. Similar wear of the spinous pro-

${ }^{*}$ Corresponding author.

How to cite this paper: Baranto, A., et al. (2016) Interspinous Process Implants Causes Wear of the Spinous Processes in Patients Treated for Spinal Stenosis-An Experimental Biomechanical Study with Comparison to Clinical Cases. Open Journal of Orthopedics, 6, 201-210. http://dx.doi.org/10.4236/ojo.2016.67027 
cesses is also present in patients treated with the same device post-operatively. How these findings influence the short and long term result of this implant device remains to be investigated in further biomechanical as well as clinical studies. For future development of this type of devices a proper selection of materials and design is essential to minimize wear effects on the spinous processes and thereby increases the possibilities for the devices to function as suggested.

\section{Keywords}

\section{Porcine, Interspinous Process Device, Cyclic Loading, Wear, Degenerative Lumbar Spinal Canal Stenos, Aperius PercLID}

\section{Introduction}

In recent years the use of Interspinous Process Devices (IPD) has increased and become a popular choice of treatment for spinal degenerative diseases especially central lumbar spinal canal stenosis [1] [2]. These implants have been suggested as an alternative to open decompression, with or without fusion. The theory of the IPD technique is to prevent collapse of the central spinal canal area and vertebral foramens at the symptomatic level. They limit extension, but still allow lateral bending and axial rotation of the treated segment and thereby are believed to have less impact on the adjacent segments when compared to fused segments [3]-[9].

A biomechanical study on different IPDs (X-Stop, Wallis, Diam and Coflex) showed that some IPDs did not alter the range of motion (ROM), except in extension, whereas all IPDs prevented hyperextension [10]. Wilke et al. [10] also demonstrated that the intradiscal pressure decreased in extension after IPD implantation. In a biomechanical study on lumbar spines from human cadavers operated with IPD a significant reduction in ROM during flexion and extension was shown, but also showed a significant increase in ROM for the lumbar spine during lateral bending and rotation [11] [12]. Although Aperius PercLID was not included in this study it is reasonable to believe that Aperius has similar effects on the vertebral motion segment where it is inserted. The IPD is therefore, allowing and preserving at least part of the original motion in the index segment.

In other situations where motion preserving or loaded implants have been used it is well known that the durability is limited, i.e. prosthesis of hip, knee, ankle, elbow as well as disc and dental implants [13]-[16]. The effect of repetitive loading of the IPDs on the spinous processes has to our knowledge not been addressed previously. Some studies are describing wear of the spinous processes as a complication [11] [12] [17] [18], but none have presented biomechanical findings or numerical analysis in patients treated with IPD.

The main purpose of this study was to investigate the Aperius implant effect on the load-bearing bone of the spinous processes on the inserted level in a biomechanical porcine model. For comparison, three patients treated surgically with the same device have been followed for one to two years clinically and with image analyses (X-rays, MRI and CT-scans).

\section{Material and Methods}

\subsection{Materials}

Four 6-month-old male domestic pigs weighing 65 - $70 \mathrm{~kg}$ were sacrificed after sedation with Ketamine (Ketalar ${ }^{\mathbb{B}}$ ) 15 - $20 \mathrm{mg} / \mathrm{kg}$ i.m. and anaesthetized with Methomidate chloride 3 - $5 \mathrm{mg} / \mathrm{kg}$ (Hypnodil ${ }^{\circledR}$ ) and Azaperon $0.1 \mathrm{mg} / \mathrm{kg}$ $\left(\right.$ Stresnil $\left.{ }^{\mathbb{}}\right)$. The lumbar spines were harvested post mortem. The muscles and adipose tissues were removed while the bone, the discs and the ligaments were carefully preserved. The lumbar spines were divided into functional spinal units (FSUs). Seven FSUs, two Th12-L1, one L1-L2 and three L4-L5 levels, were used in the present study. For comparison a control case without implantation of Aperius is also presented. The specimens were frozen at $-20^{\circ}$ Celsius until the time of testing, thawed for 12 hours before preparation and stored at $+8^{\circ} \mathrm{C}$ in a refrigerator for one to three days between the time of preparation, biomechanical testing and radiological examinations.

The soft tissue was removed from the top and bottom endplates of each specimen to facilitate mounting of the FSUs, which was done with polyester putty (Loctite Sweden AB, Gothenburg, Sweden) in testing cups. The segments were carefully mounted with the aim to achieve parallel endplate surfaces. This experimental set-up has previously been reported [19] [20]. 


\subsection{Surgical Procedure of the Implants}

The distance between the spinous processes in a porcine spine from an animal with a weight of $60 \mathrm{~kg}$ is slightly larger than in human adult spine, and clearly larger when compared to a degenerated human FSU. The available maximum size of the implants did not cause segmental distraction in an intact porcine spine. The facet joints were removed in order to prevent them restricting the loading of the spinal processes during cyclical loading. For the 7 segments, where the metal implant Aperius were used the optimal distraction of the FSU was performed by the standard trocar and dilators of different sizes (8, 10, 12 and $14 \mathrm{~mm})$ according to the surgical method described by the manufacturer. The corresponding implant size was then chosen and inserted between the spinious process and the wings were deployed on both sides. The inserter was finally detached therefore preserving the interspinous ligament.

\subsection{Mechanical Test Procedure}

The specimens were mounted between the crossheads of a testing machine (MTS Test Star, Minneapolis, MN), which was adjusted in 3 degrees of extension to achieve maximum axial load on the implant. The segments were cyclically loaded 20,000 times in pure axial compression with three cycles per seconds. The applied load was $1000 \mathrm{~N}$ in sinusoidal form 0 - $1000 \mathrm{~N}$. This experimental setup has previously been reported [19] [20]. Force and deformation were continuously recorded throughout the loading session. Deformation was defined as change in distance between the crossheads.

\subsection{CT-Scan Examinations}

The extent of wear of the spinous processes induced by the implants was determined from a CT-scan. CT-scan was chosen as investigation modality to correspond to the clinical situation and it is also the best method for detecting injuries and wear of the bone. The implants were removed from the segments before CT examination to minimize artefacts caused by the metal implants. This was done by excision of the interspinous ligaments to prevent further damage to the bony tissue. CT examinations were performed with a multi-detector CT machine (GE Lightspeed/GE Healthcare) using a slice thickness of $0.625 \mathrm{~mm}$, speed of $9.37 \mathrm{~mm} /$ rotation and a pitch of 0.938:1 at $140 \mathrm{kV}$ and $570 \mathrm{~mA}$. Transverse and sagittal CT reconstructions were used for analysis.

The wear of the interspinous processes was measured in mm on CT-scans. The most central image from the CT examination for every subject was printed. A line was then drawn from the calculated normal contour of the spinous process to the other side of the wear cavity created by the implant. The wear was defined as the distance from this line to the deepest part of the cavity in the spinous process (Figure 1). Wear of both the spinous processes (the cranial and the caudal) in each segments were measured and the total is presented.

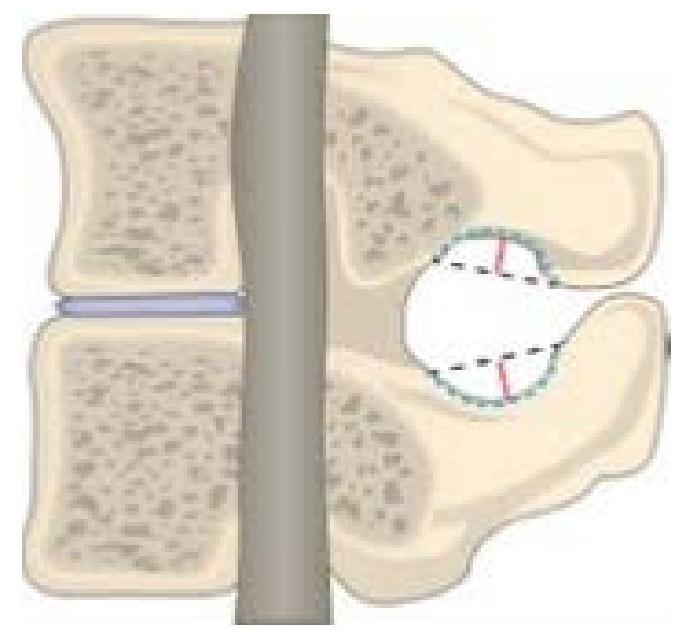

Figure 1. A drawing showing how the measurements of the wear of the spinous processes were performed. The dotted lines represent the line that was drawn from the normal contour of the spinous process to the other side of the wear cavity created by the implant. The full line represents the measurement of wear, defined as the distance from the dotted line to the deepest part of the cavity in the spinous process. 


\subsection{Patients}

To relate the biomechanical findings with clinical situations, three consecutive spinal stenosis patients with moderate or severe neurogenic intermittent claudication (NIC) undergoing surgery with Aperius implantation were used. The patients were examined with MRI to confirm diagnosis preoperatively. All three patients were operated with the Aperius implants on the affected level in LA with Ropivacain under slight sedation as a day care procedure. Postoperatively CT-scans were performed between 11 to 18 months after surgery and the wear of the spinous processes were calculated with the method described above for the ex-vivo model.

\subsection{Ethical Approval}

Approval for the use of animals in this study was granted by the Local Animal Research Ethics Committee and for the clinical cases of the Regional Ethical Review Board in Gothenburg at Sahlgrenska Academy Gothenburg, Sweden.

\section{Results}

\subsection{Experimental Biochemical Tests}

The mean maximum relative deformation in the seven studied porcine segments was $1.79 \mathrm{~mm}$ (SD 0.25$)$. The deformation curves showed a similar pattern in all cases (Figure 2 and Figure 3). The largest deformation occurred in the early phase of the loading procedure, up to 5000 cycles. Thereafter slow continuously increasing deformation was seen.

Wear of the spinous processes is present on the CT examination after biomechanical loading in all seven cases and the control case (Figure 4). The amount of wear varied between 4 to $8 \mathrm{~mm}$ (Figure 5). The mean wear of the porcine spinous process on CT examinations was $6.57 \mathrm{~mm}$ (1.62 SD).

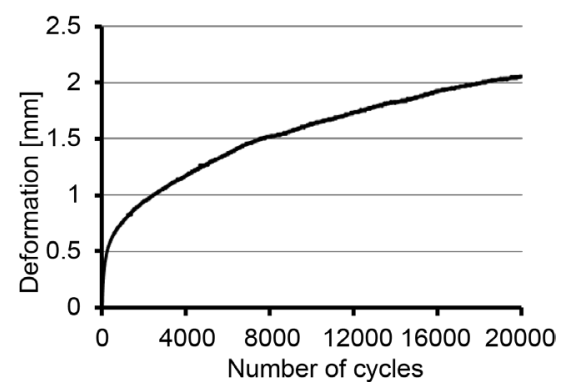

Figure 2. The deformation curve from one of the specimens (a similar pattern was seen in all cases). The largest deformation of the specimen occurred in the beginning of the cyclic load, up to approximately 5000 cycles.

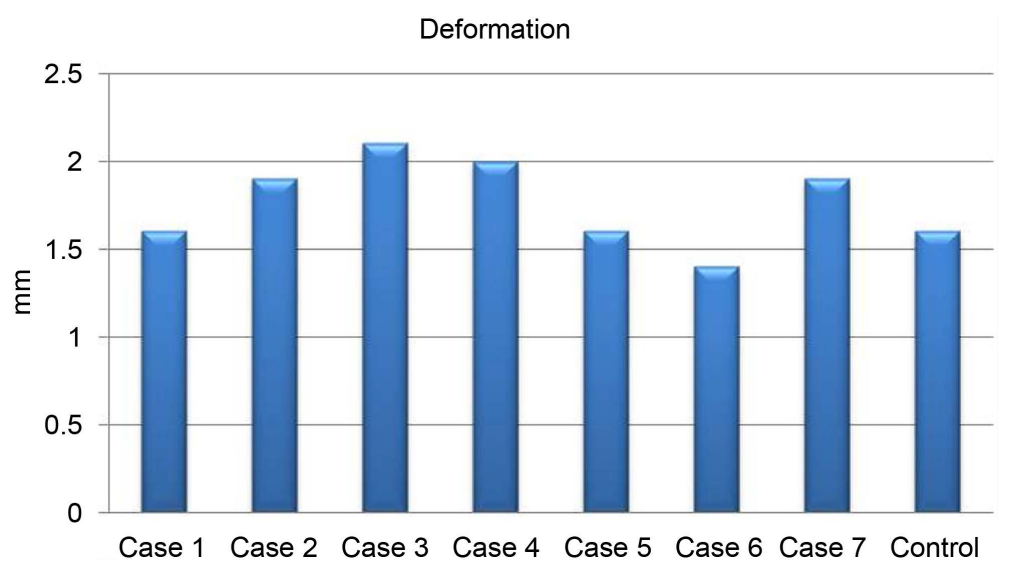

Figure 3. Deformation in mm after 20,000 cycles of loading. Mean value 1.79 $\mathrm{mm}$ and 95\% confidence Interval for the mean 1.58 - $1.96 \mathrm{~mm}$. 


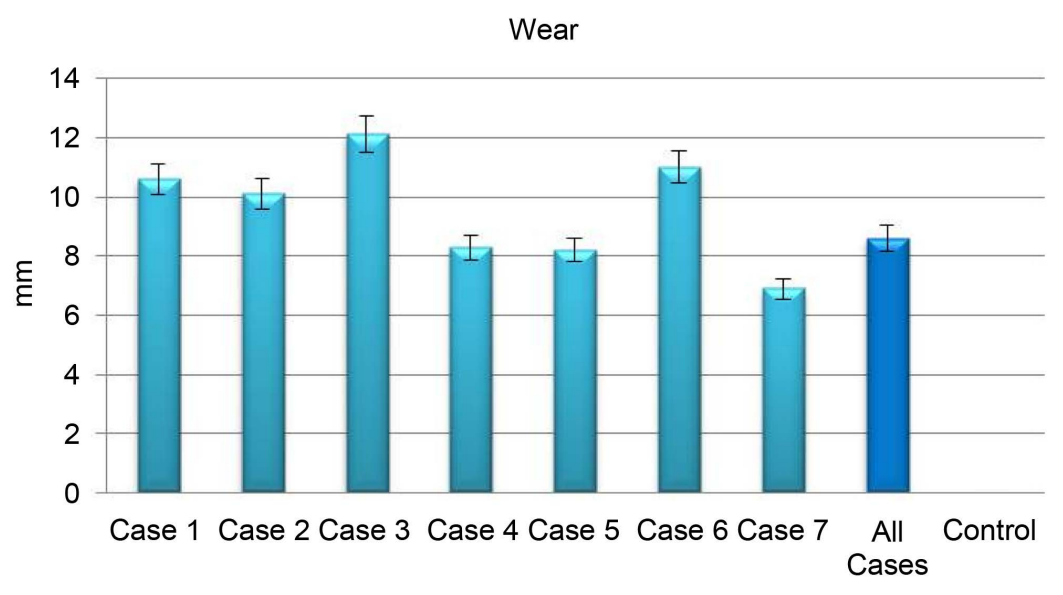

Figure 4. The calculated wear of the spinous processes on CT examinations after loadings in the seven porcine specimens. Mean $6.57 \mathrm{~mm}$ (1.62 SD).

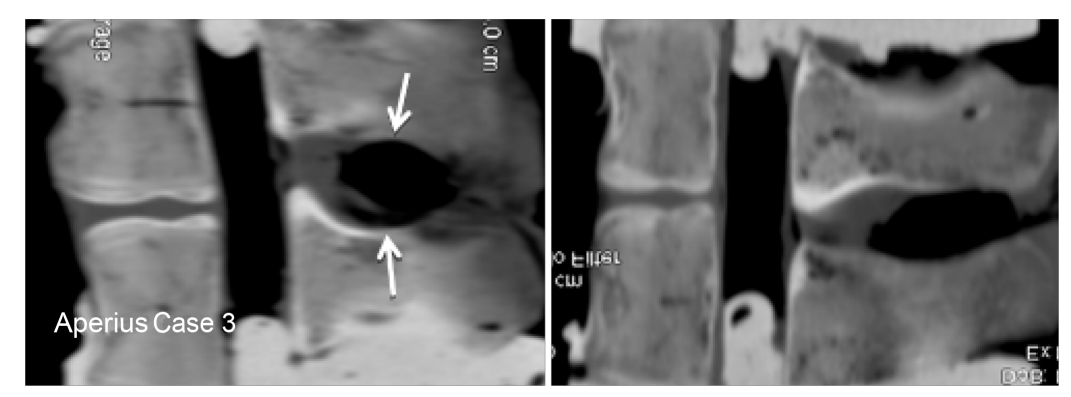

Figure 5. Left: The wear of the spinous process on CT-scans in porcine spines operated with Aperius and subjected to cyclic loading 20,000 times. The wear is marked with white arrows. Right: Control specimen.

\subsection{Clinical Cases}

\subsubsection{Patient 1}

Case 1 was a 69-year-old woman with severe NIC due to lateral lumbar spinal stenosis at the L4-L5 level on MRI. Symptoms have been apparent for more than 10 years. Moreover, during the past two years symptoms have increased and at present she can only walk a total distance of $100 \mathrm{~m}$. She was operated with Aperius on the affected level in LA with Ropivacain under slight sedation as a day care procedure. One year after the surgery the patient had a slight decrease of sensation her right foot but no other pseudoclaudication disturbances. Radicular pain in her right leg had improved as had her total walking distance. Moreover, she reported not having to use painkillers.

\subsubsection{Patient 2}

Case 2 was a 71-year-old man with severe NIC for 5 years due to spinal stenosis at the L3-L4 level. The radicular leg pain had increased and he reported a walking distance between 50 - $100 \mathrm{~m}$. He was treated with Aperius in LA with Ropivacain. His NIC symptoms in the legs recovered for two years. MRI examination showed a spinal canal diameter of $70 \mathrm{~mm}^{2}$. He reported left-sided low back pain after the procedure. Moreover, two years later, he had an episode of NIC symptoms which lasted for two months. Thereafter, the symptoms, including back pain, recovered except for some numbness in his feet.

\subsubsection{Patient 3}

Case 3 was a 41-year-old man with NIC and slight low back pain that was treated with Aperius on the index level. He had severe radicular pain in his legs that was shown to completely recover postoperatively. Although the NIC symptoms were shown to improve, in spite of this he still reported some left-sided low back pain. After approximately 1.5 years the LBP started to increase along with some numbness in his legs. Due to the fact that 
the LBP symptoms did not recovered conservatively with painkillers and physiotherapy, the patient is now candidate for Transformainal Lateral Interbody Fusion (TLIF).

Summary of the patient's results relating to symptom duration, type of pain, age, operated index level, postoperative symptom relief and amount of wear of the spinous processes are presented in the Table 1 below.

The patients reported a symptomatic duration between 2 to 10 years with significant spinal stenosis at the treated levels on MRI. One year postoperatively one patient had a recurrence of symptoms whilst the other two recovered from their preoperative NIC symptoms.

The wear of the spinous processes from eleven month to one year postoperative on CT-scans varied between 10 to $14.1 \mathrm{~mm}$ (Figure 6).

\section{Discussion}

In summery the present study demonstrated wear of the interspinous process by Aperius in an ex-vivo model with a mean of $6.57 \mathrm{~mm}$. Similar findings, with the mean wear of $11.7 \mathrm{~mm}$, were seen in three patients indicating that these findings are of clinical significance.

The principle of the interspinous implants is to increase the sagittal space between the spinous processes, thereby decreasing the load upon the facet joints and elongation of the ligamentum flavum resulting in increased intraspinal space and enlargement of the foraminal canal area, decreasing the compression on the neural structures [21].

Table 1. Patient demography, history of NIC, treated level, changes of symptoms postoperatively, duration of symptom relief, recurrence of symptoms and amount of wear of the spinous processes in three patients with lumbar spinal stenosis treated with the Aperius implant. Postop = postoperatively.

\begin{tabular}{|c|c|c|c|}
\hline & Patient 1 & Patient 2 & Patient 3 \\
\hline Sex & Female & Male & Male \\
\hline Age (Years) & 69 & 71 & 41 \\
\hline $\begin{array}{l}\text { Duration and type of } \\
\text { symptoms }\end{array}$ & $\begin{array}{c}10 \text { years } \\
\text { NIC, walking distance }<100 \mathrm{~m}\end{array}$ & $\begin{array}{c}5 \text { years } \\
\text { NIC, walking distance } 50-100 \text { m }\end{array}$ & $\begin{array}{l}2 \text { years } \\
\text { Radiating pain legs bilaterally }\end{array}$ \\
\hline Treated level & L4-L5 & L3-L4 & L4-L5 \\
\hline $\begin{array}{l}\text { Postoperative change } \\
\text { in symptoms }\end{array}$ & $\begin{array}{c}\text { 1) Improvement in leg/back pain and } \\
\text { increasing waking distance lasting for at } \\
\text { least } 1 \text { year }\end{array}$ & $\begin{array}{l}\text { 1) Improvement in NIC symptoms } \\
\text { for } 2 \text { years } \\
\text { 2) Two months period of NIC } \\
\text { symptoms } \\
\text { 3) Most NIC symptoms decreased, } \\
\text { remaining feet numbness }\end{array}$ & $\begin{array}{c}\text { 1) Almost full recovery } \\
\text { leg/back } \\
\text { 2) After } 1,5 \text { years gradually } \\
\text { increasing symptoms leg/back }\end{array}$ \\
\hline $\begin{array}{l}\text { Wear of spinous } \\
\text { processes }\end{array}$ & $\begin{array}{c}14.1 \mathrm{~mm} \\
\text { (12 month postop) }\end{array}$ & $\begin{array}{c}10.0 \mathrm{~mm} \\
\text { (11 month postop) }\end{array}$ & $\begin{array}{c}11.0 \mathrm{~mm} \\
\text { (12 month postop) }\end{array}$ \\
\hline
\end{tabular}

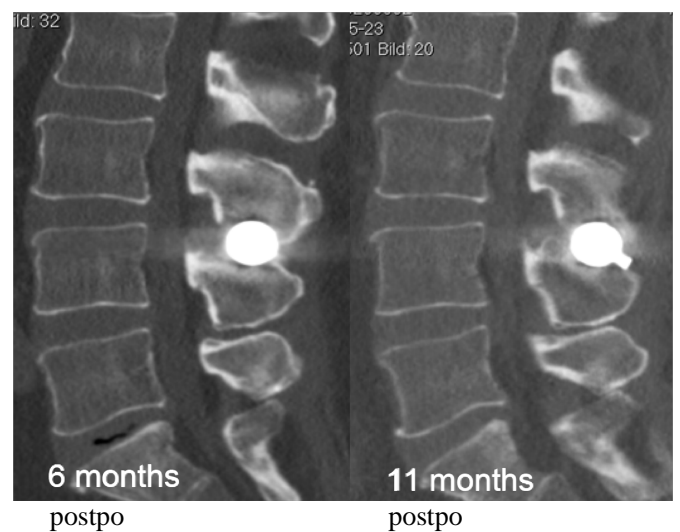

Figure 6. Seventy-one year's old man treated with Aperius and examined with CT 6 and 11 months postoperatively. The wear is clearly seen on the spinal processes both above and below the Aperius implant. 
The impact of an interspinous implant upon the load transfer in a FSU have previously been studied and pressure recordings in the disc and facet joints revealed that the load distribution in the FSU with implants shifted towards a situation where the spinous processes have a more active part in the load transfer. This is in comparison with a normal FSU where the facet joints and the intervertebral disc accounts for the majority of the load transfer [22]. By the insertion of an interspinous implant an extra load supportive structure is introduced in the FSU in addition to the three structures that normally accounts for the load support, the intervertebral disc and the two facet joints. The metal to bone contact surface that is inherently created by the spinal implant device is likely to be susceptible to wear. The loading model in this study is highly simplified when compared to a six degree of freedom loading situation that occurs in living life. However, the main goal with the in-vitro testing was to investigate the wear properties in the implant-bone structure interface. Using a pure axial compression loading model ensured that the spinous processes was provoked by the implant during each loading cycle. The study design emphasises the immediate post-operative time and uses a load range that is within the physiological boundaries.

20,000 loading cycles were chosen based on the knowledge that this is approximately the number of steps walked in one week in the modern sedentary lifestyle [20] [23]. The number of cycles was performed under a relatively short time-interval, which possibly could contribute to the volume of the wear seen. On the other hand the average implant, and adjacent bone, in weight bearing combined with cyclic loading and movement over a longer time-period more than 20,000 cycles may be expected.

The notable discrepancy between the wear values in mm obtained from the CT-images and the deformation values derived from the MTS testing machine is probably multifactorial. The resolution of the CT influences the interpretation of the images and the measurement of error is in this study is approximately $1 \mathrm{~mm}$. The requirements to achieve optimal CT-images were possibly not met since it was an ex-vivo testing situation and an isolated segment was CT examined. The specimens were stripped of muscles and other soft tissue structures which might have impaired the quality of the CT images. The deformation values from the MTS represent the movement of the actual piston during loading. If the vertebrae and fixation cups were considered to be solid, the true deformation would be attributed to the intervertebral structure. However since we selected to adjust the set-up to a 3 degrees extension angle, a non-uniform loading might have been imposed on the specimen, thereby provoking some kind of sagittal rotation secondary to the axial compression. A possible effect of this loading could have been a slight movement between the vertebrae and fixation cups. No such movement was however noted during the actual loading event.

A limitation of using biomechanical porcine study models is that the remodelling response in the bony structure during constant loading, such as in an in-vivo situation, is not included. However, this phenomenon is of limited importance compared to the wear and/or fatigue that occurs in the structure due to repetitive loading with movements. The propagation of the wear is likely to regulate at which rate and magnitude the facet joints regain their load sharing properties.

The porcine spine segments do not represent the human spine in all aspects, but can be considered a fair model to achieve an idea on how a IPD and the adjacent tissue react [24]. The facet joints were destroyed in the index segments in order to decrease the distance between the spinous processes and to adopt pressure on the implants. Wiseman et al. [25] showed that inserting an IPD relieved pressure from the facet joints suggesting that the preoperative weight bearing of the facet joints are transferred to the inserted IPD. Based on these findings, we do not believe that the procedure of facet ectomy in this model influenced the results.

The clinical importance of the observed wear of the spinous processes after the Aperius procedure is unknown. Most probably the Aperius, as well as other solid metal implants, continues to function as extension inhibitors, even though it most probably loses its potential over time, to keep the segment flexed. It may be possible that the IPDs have a temporary effect until the maximum wear has occurred. At the stage where the distance between the spinous processes has returned to the preoperative distance the indirect decompression effect, created by initial distraction, is lost.

Wear of spinous processes after IPDs has previously been described as a complication in few studies [11] [12] [17] [18]. In the present study the findings of the clinical cases were similar to the findings seen in the biomechanical testing, indicating that wear of the spinous processes is possibly an ongoing process, of varying degree, in all implanted segments. The higher figure for the wear of the spinous processes measured in the patients, compared to what was seen in the cadavers, is most probably explained by the longer duration of loading in the patients, but may also be caused by a difference in bone quality.

In the three patients investigated with imaging one of them had recurrent symptoms within two years. The 
recovery effect gained by IPD can vary from 6 months to several years [2] [26]. However, these implants may still be a good treatment option for elderly patients with low activity level and co-morbidities, where avoidance of general anaesthesia is recommended.

Based on the present experimental and clinical results future implants preferably should be constructed from appropriate materials that do not create wear and consequently minimize abrasions on the spinous processes. Preferably the implants should still be inserted under local anaesthesia, not losing its benefit compared to conventional laminectomy.

\section{Limitations}

A limitation of this study may be the short loading time with few cycles. We performed several pilot-tests both with low frequency of loading and, fewer shorter cycles. Moreover, it was decided to have a realistic amount of cycles and loading for an elderly adult population. Therefore 20,000 loading cycles were chosen based on the knowledge that this is approximately the number of steps walked in one week in the modern sedentary lifestyle. This is a very short time of loading, but to perform studies with longer duration is very time consuming and also difficult in a biomechanical testing condition. The set-up doesn't withstand unlimited cycles. The plastic padding that holds the segments in the testing cups loosens. Therefore we decided to have fewer cycles with high loading. Perhaps in the future, clinical and or experimental studies with a lower frequency will be performed.

Another limitation is that this is an ex-vivo experimental study. Therefore the biomechanical porcine model that was used cannot respond to bony remodelling during constant loading, such as in an in-vivo situation. This may affect the results in the in-vivo situation.

The small number of clinical cases presented might be a limitation. However, the wear of the spinal processes on CT-scans can be easily found on all cases. Therefore we believe that this may be occurring in all patients' that have undergone surgery with metal IPDs and may be one of the reasons for a recurrence of symptoms.

\section{Conclusion}

In conclusion, the Aperius IPD creates significant wear on the spinous processes in an experimental biomechanical study. Similar wear of the spinous processes is also present in patients treated with the same device post-operatively. How these findings influence the short and long term result of this implant device remains to be investigated in further biomechanical and clinical studies. For the future development of this type of device a proper selection of materials and design is essential to minimize the wear effect upon the spinous processes and thereby increases the possibility for the device to function as suggested.

\section{Acknowledgements}

The authors acknowledge the financial support of The Medical Society of Gothenburg, Sweden, Governmental grants under the ALF agreement, Medtronic Scandinavia for providing us with implants, Handlanden Hjalmar Svenssons Research Foundation and Doktor Felix Neuberghs Foundation.

\section{Competing Interests}

The authors have declared that no competing interests exist.

\section{Authors' Contributions}

$\mathrm{AB}$ participated in the study design, data gathering, data analysis and writing of the manuscript.CH helped with data gathering, data analysis and writing of the manuscript. JH participated in the study design, performed the biomechanical tests, gathered data, data analysis and started writing the manuscript. LE participated in the study design; help with performing the biomechanical test, data gathering, data analysis and writing of the manuscript. $\mathrm{KH}$ participated in the study design and writing of the manuscript. HB participated in the study design and writing of the manuscript.

\section{References}

[1] Siddiqui, M., Nicol, M., Karadimas, E., et al. (2005) The Positional Magnetic Resonance Imaging Changes in the 
Lumbar Spine Following Insertion of a Novel Interspinous Process Distraction Device. Spine (Phila Pa 1976), 30, 2677-2682. http://dx.doi.org/10.1097/01.brs.0000187878.79676.26

[2] Zucherman, J.F., Hsu, K.Y., Hartjen, C.A., et al. (2005) A Multicenter, Prospective, Randomized Trial Evaluating the X STOP Interspinous Process Decompression System for the Treatment of Neurogenic Intermittent Claudication: TwoYear Follow-Up Results. Spine (Phila Pa 1976), 30, 1351-1358. http://dx.doi.org/10.1097/01.brs.0000166618.42749.d1

[3] Lindsey, D.P., Swanson, K.E., Fuchs, P., et al. (2003) The Effects of an Interspinous Implant on the Kinematics of the Instrumented and Adjacent Levels in the Lumbar Spine. Spine, 28, 2192-2197. http://dx.doi.org/10.1097/01.BRS.0000084877.88192.8E

[4] Schmoelz, W., Huber, J.F., Nydegger, T., et al. (2003) Dynamic Stabilization of the Lumbar Spine and Its Effects on Adjacent Segments: An in Vitro Experiment. Journal of Spinal Disorders \& Techniques, 16, 418-423. http://dx.doi.org/10.1097/00024720-200308000-00015

[5] Frelinghuysen, P., Huang, R.C., Girardi, F.P., et al. (2005) Lumbar Total Disc Replacement Part I: Rationale, Biomechanics, and Implant types. Orthopedic Clinics of North America, 36, 293-299. http://dx.doi.org/10.1016/j.ocl.2005.02.014

[6] Cunningham, B.W., Orbegoso, C.M., Dmitriev, A.E., et al. (2003) The Effect of Spinal Instrumentation Particulate Wear Debris. An in Vivo Rabbit Model and Applied Clinical Study of Retrieved Instrumentation Cases. Spine Journal, 3, 19-32. http://dx.doi.org/10.1016/S1529-9430(02)00443-6

[7] Link, T.M. and Bauer, J.S. (2002) Imaging of Trabecular Bone Structure. Seminars in Musculoskeletal Radiology, 6, 253-261. http://dx.doi.org/10.1055/s-2002-36723

[8] McAfee, P.C., DeVine, J.G., Chaput, C.D., et al. (2005) The Indications for Interbody Fusion Cages in the Treatment of Spondylolisthesis: Analysis of 120 Cases. Spine (Phila Pa 1976), 30, S60-S65.

http://dx.doi.org/10.1097/01.brs.0000155578.62680.dd

[9] Ekman, P., Moller, H. and Hedlund, R. (2009) Predictive Factors for the Outcome of Fusion in Adult Isthmic Spondylolisthesis. Spine (Phila Pa 1976), 34, 1204-1210. http://dx.doi.org/10.1097/BRS.0b013e3181a19e66

[10] Wilke, H.J., Drumm, J., Haussler, K., et al. (2008) Biomechanical Effect of Different Lumbar Interspinous Implants on Flexibility and Intradiscal Pressure. European Spine Journal, 17, 1049-1056. http://dx.doi.org/10.1007/s00586-008-0657-2

[11] Hartmann, F., Dietz, S.O., Kuhn, S., et al. (2011) Biomechanical Comparison of an Interspinous Device and a Rigid Stabilization on Lumbar Adjacent Segment Range of Motion. Acta Chirurgiae Orthopaedicae et Traumatologiae Cechoslovaca, 78, 404-409.

[12] Hartmann, F., Dietz, S.O., Hely, H., et al. (2011) Biomechanical Effect of Different Interspinous Devices on Lumbar Spinal Range of Motion under Preload Conditions. Archives of Orthopaedic and Trauma Surgery, 131, 917-926. http://dx.doi.org/10.1007/s00402-010-1235-8

[13] Jacobs, W.C., Kruyt, M.C., Verbout, A.J., et al. (2012) Spine Surgery Research: On and beyond Current Strategies. Spine Journal, 12, 706-713. http://dx.doi.org/10.1016/j.spinee.2012.08.424

[14] Berg, S., Tropp, H.T. and Leivseth, G. (2011) Disc Height and Motion Patterns in the Lumbar Spine in Patients Operated with Total Disc Replacement or Fusion for Discogenic Back Pain. Results from a Randomized Controlled Trial. Spine Journal, 11, 991-998. http://dx.doi.org/10.1016/j.spinee.2011.08.434

[15] Pimenta, L., Oliveira, L., Schaffa, T., et al. (2011) Lumbar Total Disc Replacement from an Extreme Lateral Approach: Clinical Experience with a Minimum of 2 Years’ Follow-Up. Journal of Neurosurgery: Spine, 14, 38-45. http://dx.doi.org/10.3171/2010.9.spine09865

[16] Van den Eerenbeemt, K.D., Ostelo, R.W., van Royen, B.J., Peul, W.C. and van Tulder, M.W. (2010) Total Disc Replacement Surgery for Symptomatic Degenerative Lumbar Disc Disease: A Systematic Review of the Literature. European Spine Journal, 19, 1262-1280. http://dx.doi.org/10.1007/s00586-010-1445-3

[17] Bowers, C., Amini, A., Dailey, A.T. and Schmidt, M.H. (2010) Dynamic Interspinous Process Stabilization: Review of Complications Associated with the X-Stop Device. Neurosurgical Focus, 28, E8. http://dx.doi.org/10.3171/2010.3.FOCUS1047

[18] Miller, J.D., Miller, M.C., and Lucas, M.G. (2010) Erosion of the Spinous Process: A Potential Cause of Interspinous Process Spacer Failure. Journal of Neurosurgery: Spine, 12, 210-213. http://dx.doi.org/10.3171/2009.9.spine09144

[19] Baranto, A., Ekström, L., Hellström, M., Lundin, O., Holm, S. and Swärd, L. (2005) Fracture Patterns of the Adolescent Porcine Spine: An Experimental Loading Study in Bending-Compression. Spine, 30, 75-82. http://dx.doi.org/10.1097/00007632-200501010-00014

[20] Thoreson, O., Baranto, A., Ekstrom, L., Hellström, M., Holm, S. and Swärd, L. (2010) The Immediate Effect of Repeated Loading on the Compressive Strength of Young Porcine Lumbar Spine. Knee Surgery, Sports Traumatology, 
Arthroscopy, 18, 694-701. http://dx.doi.org/10.1007/s00167-009-1001-z

[21] Richards, J.C., Majumdar, S., Lindsey, D.P., Beaupré, G.S. and Yerby, S.A. (2005) The Treatment Mechanism of an Interspinous Process Implant for Lumbar Neurogenic Intermittent Claudication. Spine, 30, 744-749. http://dx.doi.org/10.1097/01.brs.0000157483.28505.e3

[22] Goyal, A., Goel, V.K., Mehta, A., Dick, D., Chinthakunta, R.S. and Ferrara, L. (2008) Cyclic Loads Do Not Compromise Functionality of the Interspinous Spacer or Cause Damage to the Spinal Segment: An in Vitro Analysis. Journal of Long-Term Effects of Medical Implants, 18, 289-302. http://dx.doi.org/10.1615/jlongtermeffmedimplants.v18.i4.30

[23] Tudor-Locke, C., Bassett, D.R., Swartz, A.M., et al. (2004) A Preliminary Study of One Year of Pedometer Self-Monitoring. Annals of Behavioral Medicine, 28, 158-162. http://dx.doi.org/10.1207/s15324796abm2803_3

[24] Kettler, A., Drumm, J., Heuer, F., Mack, C., Claes, L. and Wilke, H.-J. (2008) Can a Modified Interspinous Spacer Prevent Instability in Axial Rotation and Lateral Bending? A Biomechanical in Vitro Study Resulting in a New Idea. Clinical Biomechanics, 23, 242-247. http://dx.doi.org/10.1016/j.clinbiomech.2007.09.004

[25] Wiseman, C.M., Lindsey, D.P., Fredrick, A.D. and Yerby, S.A. (2005) The Effect of an Interspinous Process Implant on Facet Loading during Extension. Spine, 30, 903-907. http://dx.doi.org/10.1097/01.brs.0000158876.51771.f8

[26] Kuchta, J., Sobottke, R., Eysel, P. and Simons, P. (2009) Two-Year Results of Interspinous Spacer (X-Stop) Implantation in 175 Patients with Neurologic Intermittent Claudication Due to Lumbar Spinal Stenosis. European Spine Journal, 18, 823-829. http://dx.doi.org/10.1007/s00586-009-0967-z

\author{
Abbreviations \\ $\mathrm{CT}=$ Computed Tomograms \\ FSU = Functional Spinal Units \\ IPD = Interspinous Process Devices \\ MRI $=$ Magnetic Resonance Images \\ NIC $=$ Neurougenic Intermittent Claudication \\ $\mathrm{ROM}=$ Range of Motion
}

\title{
Submit or recommend next manuscript to SCIRP and we will provide best service for you:
}

Accepting pre-submission inquiries through Email, Facebook, Linkedin, Twitter, etc

A wide selection of journals (inclusive of 9 subjects, more than 200 journals)

Providing a 24-hour high-quality service

User-friendly online submission system

Fair and swift peer-review system

Efficient typesetting and proofreading procedure

Display of the result of downloads and visits, as well as the number of cited articles

Maximum dissemination of your research work

Submit your manuscript at: http://papersubmission.scirp.org/ 